\title{
PSYCHOLOGICAL MORBIDITY AND SELF-ESTEEM IN PATIENTS OF ACNE VULGARIS: DATA FROM A TERTIARY CARE HOSPITAL IN PAKISTAN
}

\author{
Maria Syed $^{1 \otimes}$, Muhammad Amer Saleem², \\ Abdul Wahab Yousafzai'
}

\begin{abstract}
OBJECTIVE: To assess psychological morbidity and level of self-esteem in patients of acne vulgaris.

METHODS: This cross-sectional study was conducted at Shifa International Hospital, Islamabad, Pakistan from June 2017 to December 2017. Study was approved by ethical board of Shifa hospital. One hundred and fifty-six acne vulgaris patients of both genders, aging $\geq 16$ years were selected by convenient sampling technique. Informed consent was taken from all participants. After collecting demographic details, each patient was assessed for psychological morbidity using General Health Questionnaire (GHQ- I 2) and self-esteem was measured by Rosenberg self-esteem scale (RSES). Data collected was analyzed by using SPSS version 20
\end{abstract}

RESULTS: Out of I 56 enrolled patients, I08 (69.2\%) were females and 48 $(30.8 \%)$ were males. Mean age of was $22.03 \pm 5.96$ years. Mean duration of acne was $25.69 \pm 21.74$ months. The most commonly affected area of the body with acne was face $(n=108 / 156,69.2 \%)$ followed by chest $(n=24 / 156,15.4 \%)$, shoulders $(n=13 / 156,8.3 \%)$ and back $(n=11 / 156,7.1 \%)$. A dominant proportion of the sample had positive family history of acne (82/I56, $52.6 \%$ ), were unmarried $(118 / 156,75.6 \%)$ and had a good educational background [graduates $=53 / 156(34.0 \%)$ ]. A total of $27(17.3 \%)$ patients had low esteem reported as per RSES and 146 (93.6\%) were labelled as having psychological morbidity as per GHQ-12 scale. Fisher's exact test showed no statistical significance between low esteem and psychological morbidity $(p=0.2126)$.

CONCLUSION: The patients suffering from acne can suffer from low selfesteem. However, the proportion of patients having psychological morbidity because of acne is much higher and independent of self-esteem.

KEY WORDS: Self Esteem (MeSH); Self Concept (MeSH); Acne Vulgaris (MeSH); Psychological morbidity (Non-MeSH); Rosenberg self-esteem scale (Non-MeSH); General Health Questionnaire (Non-MeSH); Morbidity (MeSH); Stress, Psychological (MeSH); Adult (MeSH); Social Isolation (MeSH).

THIS ARTICLE MAY BE CITED AS: Syed M, Saleem MA, Yousafzai AW. Psychological morbidity and self-esteem in patients of acne vulgaris: data from a tertiary care hospital in Pakistan. Khyber Med Univ J 2020;12(I):34-7. DOI: 10.35845/kmuj.2020.19121.

\section{INTRODUCTION}

A cne vulgaris also known as acne, zits or pimples is a common chronic disorder of the skin that results from the clogging of pilosebaceous units on the skin with dead cells and oil.' It is the most common skin problem encountered by dermatologists in their outdoor clinics. ${ }^{2}$ The presentation can be in the form of comedones, papules or cysts that usually appear on the face or trunk. It greatly affects the appearance and the outlook of the person. Appearance of a person has a very great impact on the self-esteem. The attitude
I. Shifa College of Medicine, Islamabad, Pakistan.

2. Benazir Bhutto Hospital, Rawalpindi, Pakistan.

Email『: maria.syed44@gmail.com

Contact \# : +92-321-5402682

$\begin{array}{ll}\text { Date Submitted: } & \text { March 16, 2019 } \\ \text { Date Revised: } & \text { February 28, 2020 } \\ \text { Date Accepted: } & \text { February 29, 2020 }\end{array}$

and approach of a person towards life is greatly influenced by ones looks. As acne negatively affects the outlooks of a person, it is thought to bring social isolation with a decrease in self-esteem.

Moreover, acne usually affects the young population mostly teenagers (peak 16-18 years of age). ${ }^{3}$ This juvenile age is very vulnerable. Youngsters are in a phase of developing and shaping up their personalities. Any negative experiences that are faced during this period usually have long lasting effects on the body and mind of a teenager. Acne is one of those side effects that are brought up by rapid hormonal changes in adolescent. It is accompanied by anger, anxiety and depression. It is suggested that acne triggers a poor selfbody image in the mind of the sufferers and results in low self-esteem and psychological morbidity. 4,5

Though impairment in quality of life by acne is well established, there is no data to suggest the prevalence of low selfesteem in our population suffering from acne. Moreover, our study is designed to give an insight into the extent of our population facing psychological morbidity because of this menace. We have also analyzed the correlation of low esteem and psychological morbidity in this study.

\section{METHODS}

This cross sectional study was conducted on patients of acne that presented to Shifa International Hospital, Islamabad, Pakistan with primary complaint of acne using convenient sampling technique from June 2017 to December 2017. The study was approved by the ethical review board of the hospital. A 
TABLE I: DEMOGRAPHIC AND CLINICAL CHARACTERISTICS OF STUDY PARTICIPANTS

\begin{tabular}{|l|l|c|c|}
\hline \multicolumn{2}{|l|}{ Variables } & Frequency & Percentage \\
\hline \multirow{4}{*}{ Gender } & Male & 48 & 30.8 \\
\cline { 2 - 4 } & Female & 108 & 69.2 \\
\hline \multirow{4}{*}{ Site of Acne } & Face & 108 & 69.2 \\
\cline { 2 - 4 } & Chest & 24 & 15.4 \\
\cline { 2 - 4 } & Shoulder & 13 & 8.3 \\
\cline { 2 - 4 } & Back & 11 & 7.1 \\
\hline \multirow{3}{*}{ Family History } & Yes & 82 & 52.6 \\
\cline { 2 - 4 } & No & 74 & 47.4 \\
\hline \multirow{3}{*}{ Education Level Status } & Married & 38 & 24.4 \\
\cline { 2 - 4 } & Unmarried & 118 & 75.6 \\
\cline { 2 - 4 } & Did not go to school & 21 & 31.5 \\
\cline { 2 - 4 } & Up to SSC* & 37 & 23.7 \\
\cline { 2 - 4 } & Up to HSSC** & 45 & 28.8 \\
\cline { 2 - 4 } & Graduation & 53 & 34.0 \\
\hline
\end{tabular}

*SSC=Secondary School Certification; **HSSC=Higher Secondary School Certification

TABLE II: ASSOCIATION OF SELF ESTEEM WITH PSYCHOLOGICAL MORBIDITY IN ACNE VULGARIS PATIENTS

\begin{tabular}{|l|c|c|c|c|}
\hline \multirow{2}{*}{ Self-Esteem } & \multicolumn{2}{|c|}{ Psychological Morbidity } & \multirow{2}{*}{ Total } & \multirow{2}{*}{ P-Value* } \\
\cline { 2 - 3 } & Yes & No & & \\
\hline Low & 27 & 0 & 27 & \multirow{2}{*}{0.2120} \\
\hline Unaffected & 119 & 10 & 129 & \\
\hline Total & 146 & 10 & 156 & \\
\hline
\end{tabular}

*Fisher's Exact Test

questionnaire was given to the patients after taking informed consent and they were allowed to fill it with no time limit and in a separate room having the comfort and isolation needed to respond to the questions efficiently.

The inclusion criteria were adults aged 16 years and above of both genders with acne vulgaris as primary complain. Those patients who had some other medical condition as epilepsy, heart disease, were excluded along with those who didn't give consent or didn't allow the dermatologist to do a clinical examination.

The participants were given a form to fill in their demographic details and then were given a two-part questionnaire. The first part of questionnaire consisted of Rosenberg's self-esteem scale (RSES). This scale consists of 10 closed ended questions, $50 \%$ of them evaluate the positive feelings and the other half evaluates the negative feelings that a person may have about himself. It was developed by Rosenberg and revised by Hutz and is an excellent tool for evaluating the self-esteem. ${ }^{6}$ According to the RSES scoring system a score of 030 can be marked for a subject. A score from 15 to 25 is taken as normal. However, a score below 15 suggests low esteem.

The second part of questionnaire was General Health Questionnaire (GHQ12) Proforma consisting of 12 questions that assess the psychological morbidity in an individual. ${ }^{7}$ The half set of questions are positively phrased and half are negatively phrased. It has been tested to be very sensitive in determining psychological morbidity. ${ }^{8}$

Similarly, according to GHQ- 12 scoring system a score of greater than two suggest that the patient has psychological morbidity. The data was entered and evaluated by SPSS version23. The fisher's exact test was used to see the relationship between selfesteem as determined by RSES and psychological morbidity reported as per GHQ- 12 questionnaire.

\section{RESULTS}

A total of 156 subjects participated in the study. Among them, 108 (69.2\%) participants were females and 48 $(30.8 \%)$ were males. The mean age of the study population was $22.03 \pm 5.96$ years. The mean duration of acne was $25.69 \pm 21.74$ months. Mostly the subjects had face involvement with acne affecting the region in about 108 (69.2\%) of the individuals. Upper chest was the second most common site affecting 24 (15.4\%) patients. A dominant proportion of the sample had positive family history of acne $(n=82$, $52.6 \%$ ). Most of the participants were unmarried $(n=118,75.6 \%)$ and had a good educational background. Out of I56 patients, 2 I (3I.5\%) subjects did not attend school (Table I).

The mode RSES score of the population was 24 and the mode GHQ- 12 score was 7. Twenty-seven (17.3\%) participants had a RSES score of less than 15 and were labelled as suffering from low esteem. Only 10 (6.4\%) subjects scored $\leq 2$ on GHQ- I 2. Rest of the subjects had a score $>2$ and were labelled as having psychological morbidity $(n=146,93.6 \%)$. All the patients $(n=27)$ who showed low selfesteem also had psychological morbidity.

Association of self-esteem with psychological morbidity in acne vulgaris patients is given in Table II.

\section{DISCUSSION}

Acne is a common dermatological condition in adults, but its effects on mental health are poorly understood. The available literature points towards the fact that individual suffering from acne has functional impairment besides psychological and emotional morbidity. The effects of acne are more emotionally damaging for women than men, more so in younger age-group. ${ }^{9}$ In addition to diminished quality of life and lower self-esteem, depression and anxiety have been found more prevalent in patients with acne vulgaris. ${ }^{10}$ Some studies demonstrated the direct association of severity of acne and post acne scaring with severity of depression particularly in female gender." The association has been found to be linear in nature, mostly proportionate to the severity of acne. 
The data on correlation of acne with self-esteem and psychological morbidity is very limited in our country. A number of studies done in Pakistan showed a significant positive relationship of acne and psychological morbidity, however self-esteem was not evaluated. ${ }^{12-14}$ All of these studies found a large proportion of patients with acne having psychological morbidity. The psychological morbidity reported in our study in way higher than previously reported studies. The explanation to this can be found in the sample distribution of our study as most of the patients in our study were females and the mean age was in 20 s. As reported by previous studies this group is at highest risk of developing psychological morbidity due to acne. Additionally, over the last few years, people have become more concerned about their appearance particularly due to frequent social media appearances or it could just be a reflection of how anxiety, depression, suicidal ideation and other psychological disorders have soared high up in our country over the last few years.

Self-esteem is described as the overall subjective emotional evaluation of people of their own worth. Though, a number of studies have found that acne causes low self-esteem, few of them have demonstrated no significant effect of acne on self-esteem. ${ }^{15}$ This is evident from our study too, as proportion of patients with low self-esteem was very minute as compared to those having psychological morbidity. Independent of low self-esteem, patients suffering from acne can have a high risk of developing psychological morbidity. Therefore, it can be concluded that many other factors play a role in developing psychological morbidity in patients with acne apart from low self-esteem. A study found that quality of life in patients with skin diseases is affected much more by psychological morbidity as compared to low self-esteem. ${ }^{16}$ So very low quality of life in patients with acne can be attributed to the high rate of psychological morbidity in them independent of self-esteem. This also implicates that treating patients of acne with isotretinoin (a commonly used medicine for acne in our country) should be well-weighted decision as depression is one of its major side effects. Some patients might need to see a psychiatrist as importantly as they have to consult a dermatologist for the treatment of acne.

Health is described as a state of complete well-being of body and mind. Acne affects the patient both physically and psychologically. Acne is a completely treatable condition and recent advances in medicine have made its treatment easy, accessible, cheap and convenient. By treating acne promptly and efficiently, dermatologists can play a pivotal role in the psychological wellbeing of our society.

The limitations of our study include limited number of patients in sample, reliance on a single scale for measuring self-esteem (RSES) and psychological morbidity (GHQ-I2) and limitations associated with the use of these individual scales.

\section{CONCLUSION}

Our study demonstrate that large proportion of patients suffering from acne vulgaris have psychological morbidity. Furthermore, the association of lower self-esteem with acne is not significant in our data. The psychological morbidity also seems to be independent of self-esteem and affects almost all the patients of acne equally, whether, their self-esteem is affected or not.

\section{REFERENCES}

I. Webster GF. The pathophysiology of acne. Cutis 2005;6(2 Suppl):4-7.

2. Baldwin HE. The interaction between acne vulgaris and the psyche. Cutis 2002;70(2): I33-9.

3. Adebamowo CA, Spiegelman D, Berkey CS, Danby FW, Rockett HH, Colditz GA, et al. Milk consumption and acne in adolescent girls. Dermatol Online J 2006; I 2(4).

4. Dalgard F, Gieler U, Holm JØ, Bjertness E, Hauser S. Self-esteem and body satisfaction among late adolescents with acne: results from a population survey. J Am Acad Dermatol 2008;59(5):746-5I. DOI: 10.1016/j.jaad.2008.07.013.
5. Smithard A, Glazebrook C, Williams HC. Acne prevalence, knowledge about acne and psychological morbidity in mid-adolescence: a community-based study. $\mathrm{Br} J$ Dermatol 200I; I45(2):274-9. DOI: I0. I046/j. I 365-2 I 33.200 I.04346. $\mathrm{x}$.

6. Sinclair SJ, Blais MA, Gansler DA, Sandberg E, Bistis K, LoCicero A. Psychometric properties of the Rosenberg Self-Esteem Scale: Overall and across demographic groups living within the United States. Eval Health Prof 20I0;33(I):56-80. DOI: 10.1I77/ 0163278709356187.

7. Gnambs T, Staufenbiel T. The structure of the General Health Questionnaire (GHQ-I2): two meta-analytic factor analyses. Health Psychol Rev 20 I 8; I 2(2): I 7994. DOI: I0.1080/I7437/99.20I8. 1426484.

8. Pevalin DJ. Multiple applications of the GHQ- 12 in a general population sample: an investigation of longterm retest effects. Soc Psychiatry Psychiatr Epidemiol 2000;35(I I): 508-12. DOI: $10.1007 / \mathrm{s} 0012700$ 50272.

9. Fernandez Obregon AC. Azithromycin for the treatment of acne. Int J Dermatol 2000;39(I):4550. DOI: $10.1046 /$ j. I365-4362. 2000.00749.x.

10. Yazici K, Baz K, Yazici AE, KöktürkA, Tot S, Demirseren D, et al. Diseasespecific quality of life is associated with anxiety and depression in patients with acne. J Eur Acad $D$ e $r m$ a tol Ve nereol 2004; I 8(4):435-9. DOI: 10. | | | |/j. | 468-3083.2004.00946.x.

II. Mishra N, Rastogi MK, Gahalaut P, Srivastava N, Aggarwal A. Assessment of depression in patients of acne vulgaris and its correlation with severity of acne, post acne scarring and gender. J Pak Assoc Dermatol 20 18;27(4):3 I3-9.

12. Khan MZ, Naeem A, Mufti KA. Prevalence of mental health problems in acne patients. J Ayub Med Coll Abbottabad 200 I; 13(4):78. 
13. Shakoor A, Shaheen JA, Khan Jl. Association of anxiety and depression with acne: evaluation of pathoplastic effect of adolescence on this comorbidity. J Pak Assoc Dermatol 20I2;22(4):336-4I.

14. Dogar IA, Man MA, Bajwa A, Bhatti $A, N$ aseem $S$, Kausar $S$.
Dermatological disorders; Psychiatric co-morbidity. Professional Med J 2010;17(02): 334-9.

15. Gallitano SM, Berson DS. How Acne Bumps Cause the Blues: The Influence of Acne Vulgaris on SelfEsteem. Int J Womens Dermatol
2018;4(I):12-7. DOI: $10.1016 / \mathrm{j}$ ijwd.2017.10.004.

16. Farshi MG, Sharifi HP, Rad MA. The relationship between self-esteem, mental health and quality of life in Patients with skin diseases. Asian Med Pharm Res 20 I3;3(2):50-4.

\section{AUTHORS' CONTRIBUTIONS}

Following authors have made substantial contributions to the manuscript as under:

MS: Conception and study design, acquisition of data, drafting the manuscript, final approval of version to be published.

MAS: Analysis of data, drafting the manuscript, final approval of version to be published.

AWY: Conception and study design, analysis and interpretation of data, drafting the manuscript, critical review, final approval of version to be published.

Authors agree to be accountable for all aspects of the work in ensuring that questions related to the accuracy or integrity of any part of the work are appropriately investigated and resolved.

CONFLICT OF INTEREST
Authors declared no conflict of interest
GRANT SUPPORT AND FINANCIAL DISCLOSURE
NIL

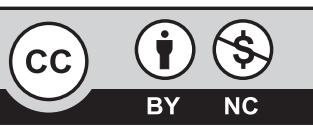

This is an Open Access article distributed under the terms of the Creative Commons Attribution-Non Commercial 2.0 Generic License.

KMUJ web address: www.kmuj.kmu.edu.pk

Email address: kmuj@kmu.edu.pk 